\title{
Measurement of the vascular pedicle width predicts fluid repletion: a cross-sectional comparison with inferior vena cava ultrasound and lung comets
}

Nawal Salahuddin ${ }^{1 *}$, Iqbal Hussain ${ }^{1}$, Hakam Alsaidi ${ }^{1}$, Quratulain Shaikh', Mini Joseph², Hassan Hawa ${ }^{1}$ and Khalid Maghrabi ${ }^{1}$

\begin{abstract}
Background: Determination of a patient's volume status remains challenging. Ultrasound assessments of the inferior vena cava and lung parenchyma have been shown to reflect fluid status when compared to the more traditional static and dynamic methods. Yet, resource-limited intensive care units (ICUs) may still not have access to bedside ultrasound. The vascular pedicle width (VPW) measured on chest radiographs remains underutilized for fluid assessment. In this study, we aimed to determine the correlation between ultrasound assessment and vascular pedicle width and to identify a discriminant value that predicted a fluid replete state.

Methods: Eighty-four data points of simultaneous VPW and inferior vena cava measurements were collected on mechanically ventilated patients. VPW measurements were compared with lung comet scores, fluid balance, and a composite variable of inferior vena cava diameter greater than or equal to $2 \mathrm{~cm}$ and variability less than $15 \%$.

Results: A VPW of $64 \mathrm{~mm}$ accurately predicted fluid repletion with a positive predictive value equal to $88.5 \%$ and an area under the curve (AUC) of $0.843,95 \% \mathrm{Cl} 0.75-0.93, p<0.001$. VPW closely correlated with inferior vena cava diameter (Pearson's $r=0.64, p=<0.001$ ). Poor correlations were observed between VPW and lung comet score, Pearson's $r=0.12, p=0.26$, fluid balance, Pearson's $r=0.3, p=0.058$, and beta natriuretic peptide, Pearson's $r=0.12$, $p=0.26$.

Conclusions: This study shows a high predictive ability of the VPW for fluid repletion, as compared to an accepted method of volume assessment. Given the relationship of fluid overload and mortality, these results may assist fluid resuscitation in resource-limited intensive care units.
\end{abstract}

Keywords: Vascular pedicle width, Inferior vena cava, Ultrasound, Fluid assessment

\section{Background}

Intravenous boluses of fluids are traditionally used to resuscitate hemodynamic instability, acute oliguria, and hyperlactatemia in the intensive care unit (ICU). However, overzealous fluid administration leads to organ congestion, organ failure, and an increased risk of death [1-8]. Currently, a variety of tools, such as central venous and pulmonary capillary wedge pressures,

\footnotetext{
* Correspondence: salahuddin.nawal@gmail.com

${ }^{1}$ Adult Critical Care Medicine, King Faisal Specialist Hospital and Research

Centre, Riyadh, Saudi Arabia

Full list of author information is available at the end of the article
}

transpulmonary thermodilution, echocardiography and ultrasound of the inferior vena cava (IVC) and lung parenchyma are commonly used to gain information about volume status and guide fluid therapy. Bedside ultrasound to measure IVC diameter, variability with respiration [9-21], and extravascular lung water as determined by the presence of $\mathrm{B}$ lines or lung comets [22-29] have been shown to closely correlate with the more traditional methods of fluid assessment, such as central venous pressure, stroke volume, and pulse pressure variation. The reliability and ease of measurement of IVC and lung parenchyma ultrasound has led to 
widespread adoption by ICU physicians to assist in bedside assessment of volume status.

Yet, not all physicians have access to these tools; ICUs in resource-limited settings have to function without many of these facilities [30-32] and may be one of the factors contributing to inability to implement resuscitation guidelines [33] and higher severity-adjusted casefatality rates [34, 35]. Nevertheless, the basic principles of fluid management can still be practiced if physicians can use the tools available to them to assess volume status.

Chest radiographs are normally available to most physicians. The vascular pedicle width (VPW) as seen on chest radiographs represents the mediastinal silhouette of the central vessels. It is easily measured and has been shown to correlate well with invasive hemodynamic measurements [36-38]. We therefore carried out this prospective, cross-sectional study to identify vascular pedicle width measurements that could discriminate fluid repletion as defined by inferior vena cava ultrasound measurements and fluid overload as defined by lung water on ultrasound.

\section{Methods}

In a prospective, cross-sectional design, consecutive adult patients on controlled mechanical ventilation admitted to the surgical and medical ICUs were included. Patients with valvular heart disease, congestive heart failure, pulmonary hypertension, pericardial disease, and a history of thoracic or cardiac surgery, requiring positive end-expiratory pressures (PEEP) higher than $5 \mathrm{~cm}$ water, and pregnancy were excluded. Simultaneous supine, standardized chest radiographs, and ultrasound assessments of the IVC and lung parenchyma were done. For all patients included in the study, conventional portable, supine, anteroposterior chest radiographs were obtained on each patient within an hour of the ultrasound measurements. The radiographic technique involved a 40inch source-image distance (SID), $60-70 \mathrm{kV}$ peaks, and a typical 3- to 6-mA exposure adjusted to patient body habitus. Each radiograph was processed in a standard rapid processor with a processor time of $45 \mathrm{~s}$. We attempted to adjust for confounding due to variation in chest radiograph technique by limiting the inclusion to very strictly standardized films as regards patient positioning, angle, ventilatory parameters, exposure, film distance, and the quality of film.

To eliminate interobserver variability, a single investigator $(\mathrm{IH})$, with training and experience in critical care ultrasound, carried out all the ultrasound examinations. All VPW measurements were obtained by an investigator (NS) blinded to clinical and ultrasound data.

The study protocol was approved by the institutional research ethics committee (RAC approval no. 2141039), and the study was performed in accordance with the ethical standards laid down in the 1964 Declaration of Helsinki and its later amendments. Informed consent to participate and consent to publish was obtained from the attendant family or designated patient representatives and documented in the medical record.

\section{Measurement of the inferior vena cava diameter, and respiratory variation by ultrasound}

Ultrasonographic assessment of the IVC was carried out using a transthoracic, subcostal approach. The transducer was positioned just below the xiphisternum 1$2 \mathrm{~cm}$ to the right of the midline, with the marker dot pointing towards the sternal notch. After obtaining a two-dimensional image of the IVC entering the right atrium and verifying that the IVC visualization was not lost during movements of respiration, an M-mode line was placed through the IVC $1 \mathrm{~cm}$ caudal from its junction with the hepatic vein and an M-mode tracing obtained. This placement ensures that the intrathoracic IVC is not measured during any part of the respiratory cycle. The M-mode tracing was recorded through three to four respiratory cycles, the image frozen, and using calipers, the maximum and minimum diameters of the IVC tracing measured. IVC respiratory variation was quantified by measuring the percent difference between the maximum and minimum diameters on the M-mode tracing.

\section{Lung ultrasound and quantification of B lines: lung comet score}

Bilateral lung comet score was obtained by scanning eight anterolateral quadrants with the probe longitudinally applied perpendicular to the wall. Each hemithorax was divided in four areas: two anterior areas and two lateral areas. The anterior chest wall (zone 1) was delineated from the parasternal to the anterior axillary line and was divided into upper and lower halves, from the clavicle to the third intercostal space and from the third to the diaphragm. The lateral area (zone 2) was delineated from the anterior to the posterior axillary line and was divided into upper and basal halves. The sum of lung comets (B lines) found on each scanning site (0: absence; 1: B3 lines, multiple B lines $3 \mathrm{~mm}$ apart; 2: B7 lines, multiple $B$ lines $7 \mathrm{~mm}$ apart) yields a score from 0 to 16 (please refer to Table 1) [23].

\section{Vascular pedicle width measurement}

Vascular pedicle width was measured on standardized, portable chest radiographs obtained in the supine position. Ultrasound assessments were done within $1 \mathrm{~h}$ period of the chest radiographs. To eliminate interobserver variation, a senior pulmonary and critical care consultant (NS) who was blinded to all other patient 
Table 1 Representative calculation of lung comet score

\begin{tabular}{lll}
\hline & Ultrasound finding & Score \\
\hline Quadrant 1, right & No B lines & 0 \\
Quadrant 2, right & B3 lines & 1 \\
Quadrant 3, right & B7 lines & 2 \\
Quadrant 4, right & B3 lines & 1 \\
Quadrant 1, left & B7 lines & 2 \\
Quadrant 2, eft & B3 lines & 1 \\
Quadrant 3, left & B7 lines & 2 \\
Quadrant 4, left & B3 lines & 1 \\
Lung comet score/maximum possible score & & $10 / 16$ \\
\hline
\end{tabular}

No B lines, score $=0 ; B 3$ lines, score $=1 ; B 7$ lines, score $=2$

details measured the VPW. The vascular pedicle width was measured by dropping a perpendicular line from the point at which the left subclavian artery exits the aortic arch and measuring across to the point at which the superior vena cava crosses the right main-stem bronchus. In patients with an indistinct right border of the pedicle, the measurement was taken from the vertical, lateral border of the superior vena cava [39]. Fluid Repletion was defined as IVC diameter greater than or equal to $2 \mathrm{~cm}$ and or variation in IVC diameter less than $15 \%$ during the respiratory cycle.

\section{Statistical analysis}

VPW and IVC diameter, lung comet score, and 24-h fluid balance were separately compared using scatter plots with regression equations. R-values were determined using the Pearson coefficient. Multivariate linear regression analysis was utilized to determine the effects of lung comet score, fluid balance, and IVC diameter on VPW. Standardized coefficients were obtained to compare the relative effects of each variable on the VPW. Receiver operating characteristic (ROC) curves were utilized to determine the optimal cutoff value of VPW that identified fluid repletion, as defined by a composite variable of IVC diameter $\geq 2 \mathrm{~cm}$ and IVC variability $\leq 15 \%$. Specificity, sensitivity, and predictive values were calculated. A Bland-Altman plot was generated to check for possible bias. Analysis was performed and graphs were generated using SPSS (IBM SPSS version 22.0, Chicago, IL) software. Two-sided $p$ values $\leq 0.05$ determined statistical significance.

\section{Results}

Eighty-four data points were collected on forty-three patients. Mean age was $54.7 \pm 20$ years, and $50 \%$ patients were female. Comorbid illnesses included cirrhosis, $21 \%$ (9 patients), malignancy, $37 \%$ (16 patients), and acute renal failure, $65 \%$ (28 patients). Admission diagnoses ranged from scheduled postoperative, $63 \%$ (27 patients), to severe sepsis or shock, $44 \%$ (19 patients). All patients were intubated and mechanically ventilated at time of data collection. Mean APACHE II and SAPS II scores were $22.4 \pm 9$ and $33.4 \pm 22$, respectively. ICU and 28 day survival rates were 86 and $79 \%$ (Table 2).

Table 2 Clinical characteristics

\begin{tabular}{|c|c|}
\hline & $n=43$ \\
\hline \multicolumn{2}{|l|}{ Demographics } \\
\hline Age years & $54.7 \pm 20$ \\
\hline Female gender & $42(50 \%)$ \\
\hline APACHE II score & $22.4 \pm 9$ \\
\hline SAPS II score & $33.4 \pm 22$ \\
\hline \multicolumn{2}{|l|}{ Comorbid conditions } \\
\hline Malignancy & $16(37 \%)$ \\
\hline End-stage liver disease & $9(21 \%)$ \\
\hline Acute renal failure & $28(65 \%)$ \\
\hline Diabetes & $10(23 \%)$ \\
\hline \multicolumn{2}{|l|}{ Admitting diagnosis } \\
\hline Postoperative $^{a}$ & $27(63 \%)$ \\
\hline Severe sepsis/shock & $19(44 \%)$ \\
\hline Neurologic failure ${ }^{b}$ & $13(30 \%)$ \\
\hline Gl bleeding/hepatic encephalopathy & $6(14 \%)$ \\
\hline COPD exacerbation & $4(9 \%)$ \\
\hline Vasopressors & $23(53 \%)$ \\
\hline Mean arterial pressure $(\mathrm{mmHg})$ & $79 \pm 10.3$ \\
\hline $\mathrm{pBNP}$ & $2743(1800,9253)$ \\
\hline Serum creatinine $(\mu M / I)$ & $105 \pm 66$ \\
\hline Serum Lactate $(\mu \mathrm{M} / \mathrm{I})$ & $2.2(\mathrm{IQR} 1.6)$ \\
\hline $\mathrm{S}_{\mathrm{C}} \mathrm{VO}_{2}$ & $65 \pm 23.8$ \\
\hline Net positive fluid balance & $+1145 \mathrm{ml}(250,4527)$ \\
\hline Hourly urine output (ml/kg/h) & $0.8(0,218)$ \\
\hline Central venous pressure $\left(\mathrm{cmH}_{2} \mathrm{O}\right)$ & $8 \pm 1.7$ \\
\hline Mechanical ventilation & $43(100 \%)$ \\
\hline Peak pressure $\left(\mathrm{cmH}_{2} \mathrm{O}\right)$ & $29 \pm 4.1$ \\
\hline $\mathrm{PaO}_{2}(\mathrm{mmHg})$ & $95.4 \pm 23.3$ \\
\hline $\mathrm{FiO}_{2}$ & $0.41 \pm 0.08$ \\
\hline $\mathrm{PaO}_{2} / \mathrm{FiO}_{2}$ ratio & $235 \pm 66$ \\
\hline Tidal volume (ml) & $388 \pm 78.3$ \\
\hline \multicolumn{2}{|l|}{ Outcome } \\
\hline ICU survival & 37 (86 \%) \\
\hline 28-day survival & 34 (79 \%) \\
\hline
\end{tabular}

Data is reported as means ( \pm SD) or medians (IQR) for skewed distributions or as proportions

APACHE II Acute Physiology and Chronic Health Evaluation II, SAPS II Simplified Acute Physiology Score II, $p B N P$ pro-beta natriuretic peptide a Postoperative cases include solid organ transplantation, major abdominal surgery, orthopedic surgery, and head and neck surgery

${ }^{b}$ Includes intracranial bleeds, stroke, infections 
Mean VPW was significantly different in the group with IVC diameter $<2 \mathrm{~cm}$ compared to the group with IVC diameter $\geq 2 \mathrm{~cm} ; 63.4 \pm 12.6,80.3 \pm 11.1, p<0.001$. Similarly, mean VPW was significantly lower in the group with IVC variability $\geq 15 \%$ compared to $<15 \%$; $57 \pm 9.7,74.1 \pm 13, p<0.001$. No significant differences were observed between mean VPWs of patients with $<8 \geq$ lung comet scores, $p=0.97$.

\section{Vascular pedicle width correlations with IVC ultrasound}

The VPW closely correlated with IVC diameter (Pearson's $r=0.64, p=<0.001$ ) measured on ultrasound (Fig. 1). On multivariate linear regression, standardized coefficients demonstrated that a 0.28 (beta)-mm increase in VPW corresponds to an increase in the mean IVC diameter by $1 \mathrm{~mm}$ (Table 3 ).

A receiver operating characteristic curve was calculated to demonstrate the ability of VPW to discriminate fluid repletion as compared to a composite variable of IVC diameter $\geq 2 \mathrm{~cm}$ and IVC variability $\leq 15 \%$ ). A VPW value of $64 \mathrm{~mm}$ had an $81 \%$ sensitivity, $78 \%$ specificity for identifying fluid repletion with an area under the curve $($ AUC $)=0.843,95 \%$ CI $0.75-0.93, p<0.001$ (Fig. 2). This VPW value had a correct classification rate $=79.6 \%$, a positive predictive value $=88.5 \%$ and a negative predictive value $=66 \%$ to identify a fluid replete state.

Vascular pedicle width correlations with lung comet score, fluid balance, and pro-beta natriuretic protein No significant correlation was observed between VPW and lung comet score, Pearson's $r=0.12, p=0.26$, VPW and fluid balance, Pearson's $r=0.3, p=0.058$, or VPW and pro-beta natriuretic protein (pBNP), Pearson's $r=$ $0.12, p=0.26$ (data not shown) (Fig. 3).

A Bland-Altman plot was constructed to assess for potential bias by comparing the VPW and IVC diameter (Fig. 4). A bias of 51.1 (mean difference of VPW - IVC diameter) was observed. Additionally, the difference and average were not independent, suggesting that in patients with low fluid status, the VPW was relatively higher than the IVC diameter and the converse was true with increasing fluid status.

\section{Discussion}

In this study, we were able to demonstrate that a VPW cutoff value of $64 \mathrm{~mm}$ correctly identifies a "full" inferior vena cava and thereby fluid repletion in mechanically ventilated patients. Our comparison of the VPW against the gold standard of inferior vena cava diameter greater than $2 \mathrm{~cm}$ and loss of variation in diameter with the respiratory cycle will allow physicians in settings with no access to ultrasound to make a confident indirect assessment of fluid status. We found no relationship between extravascular lung water (as measured by lung comet score) and VPW, possibly since the development of pulmonary edema is not as simplistic and is governed by factors independent of central hydrostatic pressures, such as increased vascular permeability.

Making an accurate assessment of fluid status remains a daily challenge for every practicing intensive care physician. Though a myriad of tools have become available, accessibility is varied. At the same time, volume assessment is even more important because of increasing data

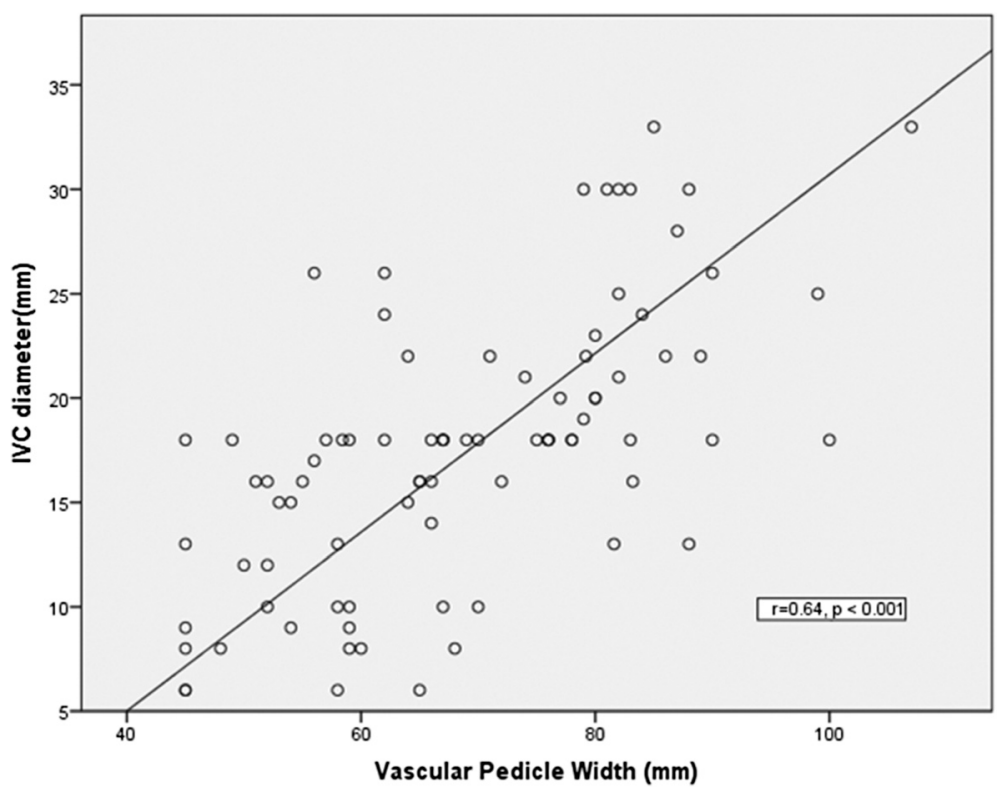

Fig. 1 Correlation between inferior vena cava diameter and vascular pedicle width. Pearson's correlation coefficient $r=0.64, p=<0.001$ 
Table 3 Results of multivariate linear regression demonstrating associations between inferior vena cava diameter, lung comet score, net fluid balance, and vascular pedicle width

\begin{tabular}{lllll}
\hline & Unstandardized coefficients B Std. error & Standardized coefficients & $95 \%$ Cl for B & $p$ value \\
\hline IVC diameter & 0.285 & 0.076 & 0.524 & $0.13,0.44$ \\
Net fluid balance & 0.002 & 0.001 & 0.181 & 0.001 .0 .003 \\
Lung comet score & 0.067 & 0.163 & 0.056 & $-0.02,0.39$ \\
\hline
\end{tabular}

identifying the risks associated with both liberal fluid administration $[1-8,40]$ and the real risks of underhydrating a dehydrated patient with a compromised microcirculation. Static haemodynamic measures, such as central venous pressure, have proved unreliable in assessing fluid status [41] but remain the mainstay of resuscitation guidelines [42]. Whilst dynamic tests that employ the interaction between respiratory mechanics and the cardio-circulatory effect of this interaction had been shown to have higher predictive values in predicting fluid responsiveness [43], they require both resources and expertise. In the last decade, inferior vena caval measurement using bedside ultrasound has gained popularity, as it is a non-invasive, dynamic test. A recent meta-analysis of studies that evaluated IVC diameter and variability demonstrated a pooled area under the receiver operating characteristic curve of 0.84 (95\% CI $0.79-0.89$ ) in identifying fluid responsiveness in mechanically ventilated patients [11].

With the widespread acceptability and description of ultrasound to determine fluid responsiveness by IVC and extravascular lung water by lung comets, ultrasound is rapidly becoming the standard of care in ICUs. However, ICUs in many low- to mid-income countries may not have bedside ultrasound available to them [30, 31]. For these resource-limited countries, it is relevant that there should be information for how well bedside ultrasound compares with methods they already have available and may be using on a routine basis. Chest radiographs are commonly done in most units, and over three decades ago, Milne described the vascular pedicle as measured on standard chest radiographs and identified a "normal" value of $48 \mathrm{~mm} \pm 5$ [44]. Since then, the VPW has been well-described to correlate with chest radiographic signs of pulmonary edema, cardiothoracic ratios, fluid balance, and echo and invasive hemodynamic measurements. Ely et al. in $100 \mathrm{ICU}$ patients described a VPW cutoff value of $70 \mathrm{~mm}$ as indicative of volume overload [45]. Martin [46] and Salahuddin et al. [47] demonstrated significant associations with fluid balance; $r=0.71, p=0.005$ and $r=0.88, p<0.001$. Thomason et al. [48] and Wichansawakul et al. [49] described significant correlations with pulmonary artery occlusion pressures (PAOP), $r=0.45, p=0.0076$ and $r=$ $0.68, p<0.001$, and cardiothoracic ratios on chest radiograph, $r=0.49, p=0.0032$. Iqbal [50] identified a cutoff VPW value $(53 \mathrm{~mm})$ and demonstrated that a left atrial emptying fraction $>0.75$ had a sensitivity of $74 \%$ and specificity of $94 \%$ for diagnosing raised intravascular volume. Aloizos et al. described a strong correlation $(0.785,0.710$, and 0.510$)$ between the VPW and PiCCOderived parameters: global end-diastolic volume index (GEDI) $p<0.001$, intrathoracic blood volume (ITBV) $p$ $<0.001$, and extravascular lung water index (ELWI) $p<$

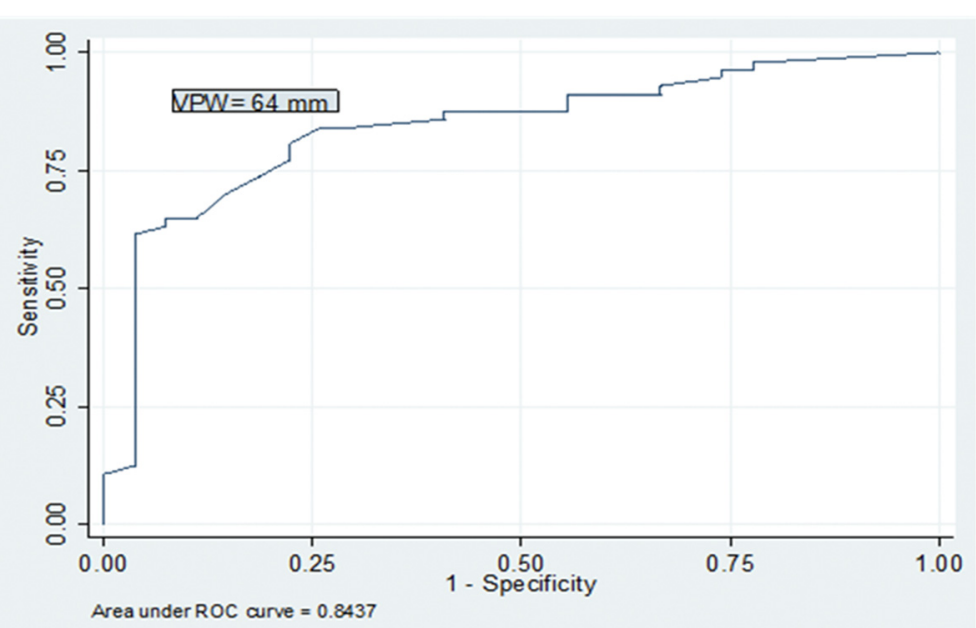

Fig. 2 Receiver operating characteristic curve of the vascular pedicle width to identify fluid repletion shows excellent diagnostic ability at an optimal VPW cutoff of $64 \mathrm{~mm}$ with area under the curve $(\mathrm{AUC})=0.843,95 \% \mathrm{Cl} 0.75-0.93, p<0.001)$ 

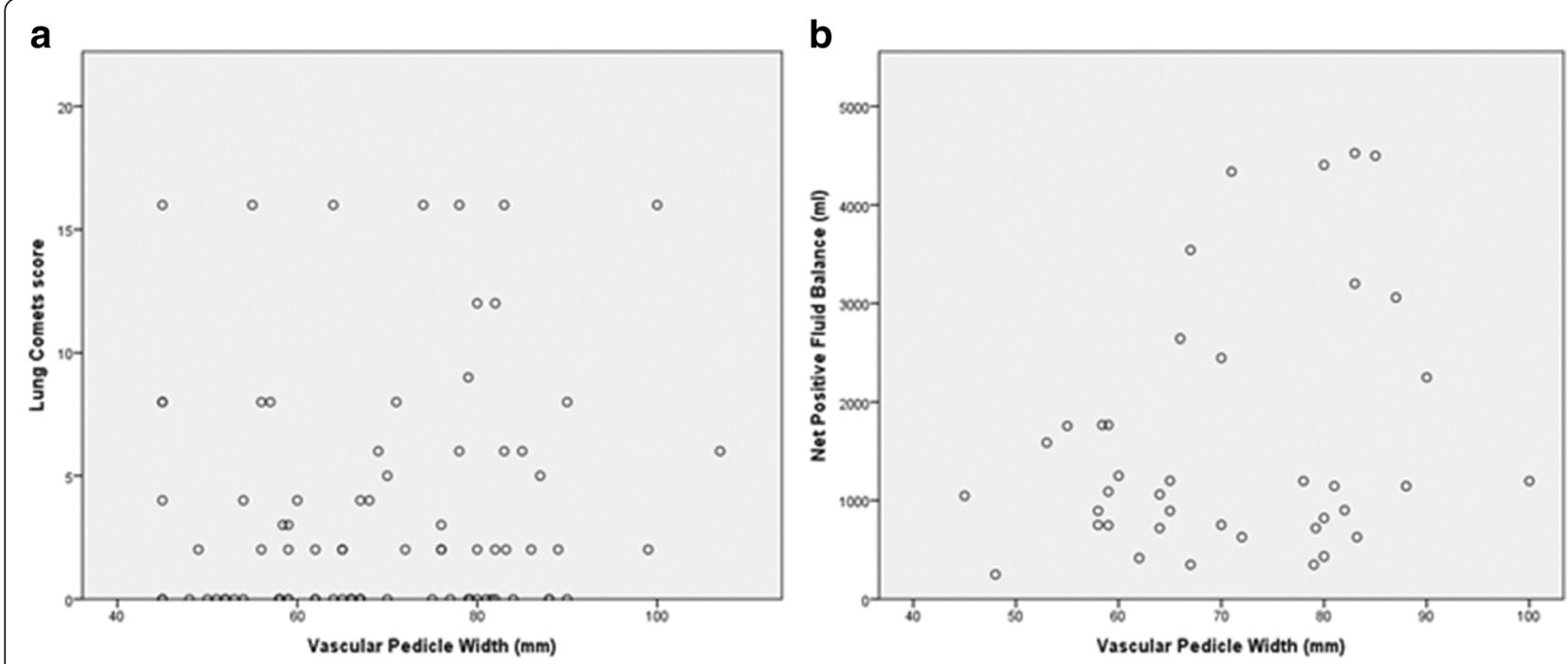

Fig. 3 Correlations between vascular pedicle width and lung comet score (a) and vascular pedicle width and net fluid balance (b)

0.005 [51]. In a meta-analysis of eight studies with 363 subjects, Wang et al. [36] summarized a strong correlation between volume overload (described by heterogeneous methods such as CVP, PAOP, chest radiograph) and VPW, $r=0.81$ (95\% CI 0.74-0.86). Though this literature provides support for use of the VPW, it does not compare with ultrasound assessment, which arguably may be considered the current standard of care. In this study, we provide one of the first descriptions of VPW with bedside ultrasound.

We were unable to show a correlation between extravascular lung water, as measured by lung comet score, and the VPW. A likely explanation for this is that in critical illness, lung water reflects vascular permeability that itself is not linearly related to increasing hydrostatic pressure (which is what the VPW represents). Patients with sepsis and systemic inflammatory response syndrome may leak fluid into the lung parenchyma and therefore have a high lung comet score but still be intravascularly "dry." Since a majority of our patients had postoperative major surgery, it is possible that widespread capillary leak was predominant, and therefore, we see this dissociation of the VPW and the lung comet scores.

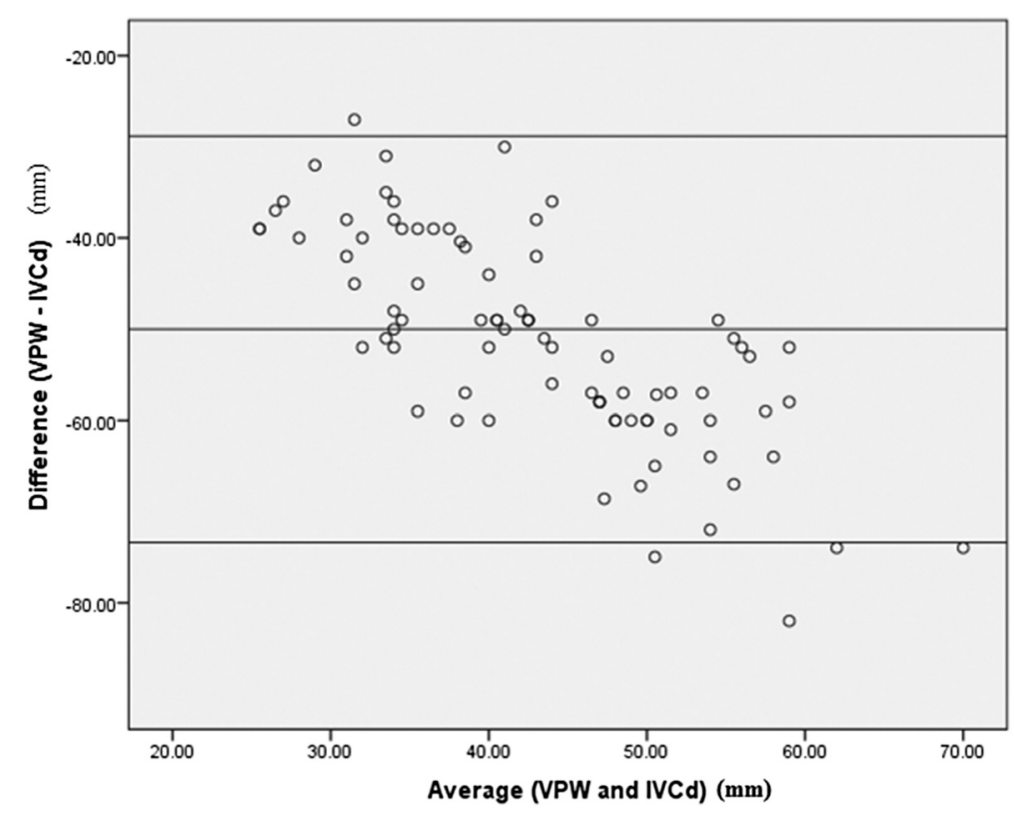

Fig. 4 Bland-Altman plot comparing the difference (VPW-IVC diameter) with the average (of VPW and IVC diameter) 
VPW measurements are simple to perform, and in a retrospective study of $80 \mathrm{ICU}$ patients, Farshidpanah et al. [37] demonstrated that novice physicians-in-training can reliably measure the VPW. Three independent raters performed measurements of VPW. Kappa statistics for inter-rater reliability showed kappa $=0.41,0.42$, and 0.85 for each pair of the three raters.

A limitation of our study is that we included patients who had no anatomic or physiologic dysfunctions that may affect measurements of the vascular pedicle [44, 52], i.e.,valvular heart disease, congestive heart failure, pulmonary hypertension, pericardial disease, and a history of thoracic or cardiac surgery. Patients on high or higher than "physiological" PEEP were excluded since previous investigators have reported that PEEP may affect the IVC measurement and collapsibility index [53, 54]. Another limitation is that most of our patients had a net positive fluid balance and high median pro-BNP values. This may have introduced a selection bias and prevented us from assessing the performance of VPW in volume-depleted patients.

\section{Conclusions}

This study shows a high predictive ability of the VPW for fluid repletion as identified by IVC ultrasound, i.e., a specified value of $64 \mathrm{~mm}$ accurately identifies a fluid replete state as defined by an IVC diameter greater than $2 \mathrm{~cm}$ and loss of IVC variability with the respiratory cycle. Therefore, the VPW may be used confidently to discriminate fluid repletion from fluid responsiveness. Given the relationship of fluid overload and mortality, these results may assist fluid resuscitation in resourcelimited ICUs.

\section{Availability of supporting data}

The dataset supporting the conclusions of this article is included within the article.

\section{Ethics approval and consent to participate}

The study protocol was approved by the institutional research ethics committee (RAC approval no. 2141039), and the study was performed in accordance with the ethical standards laid down in the 1964 Declaration of Helsinki and its later amendments. Informed consent to participate and consent to publish was obtained from the attendant family or designated patient representatives and documented in the medical record.

\footnotetext{
Abbreviations

AUC: area under the curve; ICU: intensive care unit; IVC: inferior vena cava; PEEP: positive end-expiratory pressure; ROC: receiver operating characteristic
} curves; SID: source-image distance; VPW: vascular pedicle width.

\section{Competing interests}

The authors declare that they have no competing interests.

\section{Authors' contributions}

NS conceived of the study, participated in its design and coordination, data collection, and analysis, and helped to draft the manuscript. IH participated in the study design and data collection and helped to draft the manuscript. HA participated in the study design and data collection. QS participated in the design of the study and performed the statistical analysis. $\mathrm{HH}$ and $\mathrm{KM}$ were involved in drafting the manuscript or revising it critically for important intellectual content. All authors have read and approved the final manuscript.

\section{Author details}

${ }^{1}$ Adult Critical Care Medicine, King Faisal Specialist Hospital and Research Centre, Riyadh, Saudi Arabia. ${ }^{2}$ Department of Nursing, King Faisal Specialist Hospital and Research Centre, Riyadh, Saudi Arabia.

Received: 27 August 2015 Accepted: 16 December 2015

Published online: 22 December 2015

\section{References}

1. de Almeida JP, Palomba H, Galas FR, Fukushima JT, Duarte FA, Nagaoka D, et al. Positive fluid balance is associated with reduced survival in critically ill patients with cancer. Acta anaesthesiologica Scandinavica. 2012;56(6):712-7.

2. Vaara ST, Korhonen AM, Kaukonen KM, Nisula S, Inkinen O, Hoppu S, et al. Fluid overload is associated with an increased risk for 90-day mortality in critically ill patients with renal replacement therapy: data from the prospective FINNAKI study. Crit Care. 2012;16(5):R197.

3. Wiedemann HP, Wheeler AP, Bernard GR, Thompson BT, Hayden D, de Boisblanc B, et al. Comparison of two fluid-management strategies in acute lung injury. The New England Journal of Medicine. 2006;354(24):2564-75.

4. Tsai YC, Tsai JC, Chen SC, Chiu YW, Hwang SJ, Hung CC, et al. Association of fluid overload with kidney disease progression in advanced CKD: a prospective cohort study. American Journal of Kidney Diseases. 2014;63(1): $68-75$.

5. Grams ME, Estrella MM, Coresh J, Brower RG, Liu KD. Fluid balance, diuretic use, and mortality in acute kidney injury. Clin J Am Soc Nephrol. 2011;6(5): 966-73.

6. Dass B, Shimada M, Kambhampati G, Ejaz NI, Arif AA, Ejaz AA. Fluid balance as an early indicator of acute kidney injury in CV surgery. Clinical Nephrology. 2012;77(6):438-44.

7. Magee G, Zbrozek A. Fluid overload is associated with increases in length of stay and hospital costs: pooled analysis of data from more than 600 US hospitals. Clinicoecon Outcomes Research. 2013;5:289-96.

8. Stein A, de Souza LV, Belettini CR, Menegazzo WR, Viegas JR, Costa Pereira $E M$, et al. Fluid overload and changes in serum creatinine after cardiac surgery: predictors of mortality and longer intensive care stay. A prospective cohort study. Crit Care. 2012:16(3):R99.

9. Tchernodrinski S, Lucas BP, Athavale A, Candotti C, Margeta B, Katz A, et al. Inferior vena cava diameter change after intravenous furosemide in patients diagnosed with acute decompensated heart failure. J Clin Ultrasound. 2015; 43:187-93.

10. Citilcioglu S, Sebe A, Ay MO, Icme F, Avci A, Gulen M, et al. The relationship between inferior vena cava diameter measured by bedside ultrasonography and central venous pressure value. Pak J Med Sci. 2014;30(2):310-5.

11. Zhang $Z, X u X, Y e S, X u L$. Ultrasonographic measurement of the respiratory variation in the inferior vena cava diameter is predictive of fluid responsiveness in critically ill patients: systematic review and meta-analysis. Ultrasound Med Biol. 2014:40(5):845-53.

12. Schefold JC, Storm C, Bercker S, Pschowski R, Oppert M, Kruger A, et al. Inferior vena cava diameter correlates with invasive hemodynamic measures in mechanically ventilated intensive care unit patients with sepsis. J Emerg Med. 2010;38(5):632-7.

13. Stawicki SP, Adkins EJ, Eiferman DS, Evans DC, Ali NA, Njoku C, et al. Prospective evaluation of intravascular volume status in critically ill patients: does inferior vena cava collapsibility correlate with central venous pressure? J Trauma Acute Care Surg. 2014;76(4):956-63. discussion 963-954.

14. Lanspa MJ, Grissom CK, Hirshberg EL, Jones JP, Brown SM. Applying dynamic parameters to predict hemodynamic response to volume expansion in spontaneously breathing patients with septic shock: reply. Shock. 2013;39(5):462.

15. Barbier C, Loubieres Y, Schmit C, Hayon J, Ricome JL, Jardin F, et al. Respiratory changes in inferior vena cava diameter are helpful in predicting 
fluid responsiveness in ventilated septic patients. Intensive Care Med. 2004; 30(9):1740-6.

16. Feissel M, Michard F, Faller JP, Teboul JL. The respiratory variation in inferior vena cava diameter as a guide to fluid therapy. Intensive Care Med. 2004; 30(9):1834-7.

17. Kalantari K, Chang JN, Ronco C, Rosner MH. Assessment of intravascular volume status and volume responsiveness in critically ill patients. Kidney Int. 2013;83(6):1017-28.

18. Levitov A, Marik PE. Echocardiographic assessment of preload responsiveness in critically ill patients. Cardiol Res Pract. 2012;2012:819696.

19. Machare-Delgado E, Decaro M, Marik PE. Inferior vena cava variation compared to pulse contour analysis as predictors of fluid responsiveness: a prospective cohort study. J Intensive Care Med. 2011;26(2):116-24.

20. Marik PE. Techniques for assessment of intravascular volume in critically ill patients. J Intensive Care Med. 2009;24(5):329-37.

21. Moretti R, Pizzi B. Inferior vena cava distensibility as a predictor of fluid responsiveness in patients with subarachnoid hemorrhage. Neurocrit Care. 2010;13(1):3-9.

22. Zechner PM, Aichinger G, Rigaud M, Wildner G, Prause G. Prehospital lung ultrasound in the distinction between pulmonary edema and exacerbation of chronic obstructive pulmonary disease. Am J Emerg Med. 2010;28(3):389. e381-382.

23. Agricola E, Bove T, Oppizzi M, Marino G, Zangrillo A, Margonato A, et al. "Ultrasound comet-tail images": a marker of pulmonary edema: a comparative study with wedge pressure and extravascular lung water Chest. 2005;127(5):1690-5.

24. Lichtenstein D, Meziere G. A lung ultrasound sign allowing bedside distinction between pulmonary edema and COPD: the comet-tail artifact. Intensive Care Med. 1998;24(12):1331-4.

25. Enghard P, Rademacher S, Nee J, Hasper D, Engert U, Jorres A, et al. Simplified lung ultrasound protocol shows excellent prediction of extravascular lung water in ventilated intensive care patients. Crit Care. 2015;19:36.

26. Miglioranza MH, Gargani L, Sant'Anna RT, Rover MM, Martins VM, Mantovan $A$, et al. Lung ultrasound for the evaluation of pulmonary congestion in outpatients: a comparison with clinical assessment, natriuretic peptides, and echocardiography. JACC Cardiovasc Imaging. 2013;6(11):1141-51.

27. Picano E, Frassi F, Agricola E, Gligorova S, Gargani L, Mottola G. Ultrasound lung comets: a clinically useful sign of extravascular lung water. J Am Soc Echocardiogr. 2006;19(3):356-63.

28. Shyamsundar M, Attwood B, Keating L, Walden AP. Clinical review: the role of ultrasound in estimating extra-vascular lung water. Crit Care. 2013;17(5):237.

29. Kajimoto K, Madeen $\mathrm{K}$, Nakayama T, Tsudo H, Kuroda T, Abe T. Rapid evaluation by lung-cardiac-inferior vena cava (LCI) integrated ultrasound for differentiating heart failure from pulmonary disease as the cause of acute dyspnea in the emergency setting. Cardiovasc Ultrasound. 2012;10(1):49.

30. Dunser MW, Baelani I, Ganbold L. A review and analysis of intensive care medicine in the least developed countries. Critical Care Med. 2006;34(4): $1234-42$.

31. Haniffa R, De Silva AP, Iddagoda S, Batawalage H, De Silva ST, Mahipala PG et al. A cross-sectional survey of critical care services in Sri Lanka: a lower middle-income country. J Crit Care. 2014;29(5):764-8.

32. Riviello ED, Letchford S, Achieng L, Newton MW. Critical care in resourcepoor settings: lessons learned and future directions. Crit Care Med. 2011; 39(4):860-7.

33. Cheng AC, West TE, Limmathurotsakul D, Peacock SJ. Strategies to reduce mortality from bacterial sepsis in adults in developing countries. PLoS Med. 2008:5(8):e175.

34. Silva E, Pedro Mde A, Sogayar AC, Mohovic T, Silva CL, Janiszewski M, et al. Brazilian Sepsis Epidemiological Study (BASES study). Crit Care. 2004;8(4): R251-260.

35. Mahavanakul W, Nickerson EK, Srisomang $P$, Teparrukkul $P$, Lorvinitnun $P$, Wongyingsinn $\mathrm{M}$, et al. Feasibility of modified surviving sepsis campaign guidelines in a resource-restricted setting based on a cohort study of severe S. aureus sepsis [corrected]. PloS ONE. 2012;7(2):e29858.

36. Wang H, Shi R, Mahler S, Gaspard J, Gorchynski J, D'Etienne J, et al. Vascular pedicle width on chest radiograph as a measure of volume overload: metaanalysis. West J Emerg Med. 2011;12(4):426-32.

37. Farshidpanah S, Klein W, Matus M, Sai A, Nguyen HB. Validation of the vascular pedicle width as a diagnostic aid in critically ill patients with pulmonary oedema by novice non-radiology physicians-in-training. Anaesth Intensive Care. 2014:42(3):321-9.

38. Rice TW, Ware LB, Haponik EF, Chiles C, Wheeler AP, Bernard GR, et al. Vascular pedicle width in acute lung injury: correlation with intravascular pressures and ability to discriminate fluid status. Crit Care. 2011;15(2):R86.

39. Ely EW, Haponik EF. Using the chest radiograph to determine intravascular volume status: the role of vascular pedicle width. Chest. 2002;121(3):942-50.

40. Silva Jr JM, de Oliveira AM, Nogueira FA, Vianna PM, Pereira Filho MC, Dias $L F$, et al. The effect of excess fluid balance on the mortality rate of surgical patients: a multicenter prospective study. Crit Care. 2013;17(6):R288.

41. Bendjelid K, Romand JA. Fluid responsiveness in mechanically ventilated patients: a review of indices used in intensive care. Intensive care medicine. 2003:29(3):352-60.

42. Antonelli M, Levy M, Andrews PJ, Chastre J, Hudson LD, Manthous C, et al. Hemodynamic monitoring in shock and implications for management. International Consensus Conference, Paris, France, 27-28, April 2006. Intensive Care Med. 2007;33(4):575-90.

43. Michard F, Boussat S, Chemla D, Anguel N, Mercat A, Lecarpentier Y, et al. Relation between respiratory changes in arterial pulse pressure and fluid responsiveness in septic patients with acute circulatory failure. Am J Respirat Crit Care Med. 2000;162(1):134-8.

44. Milne EN, Pistolesi M, Miniati M, Giuntini C. The vascular pedicle of the heart and the vena azygos. Part I: The normal subject. Radiology. 1984;152(1):1-8.

45. Ely EW, Smith AC, Chiles C, Aquino SL, Harle TS, Evans GW, et al. Radiologic determination of intravascular volume status using portable, digital chest radiography: a prospective investigation in 100 patients. Critical Care Med. 2001;29(8):1502-12.

46. Martin GS, Ely EW, Carroll FE, Bernard GR. Findings on the portable chest radiograph correlate with fluid balance in critically ill patients. Chest. 2002; 122(6):2087-95

47. Salahuddin NAM, Chishti I, Siddiqui S. Determination of intravascular volume status in critically ill patients using portable chest X-rays: measurement of the vascular pedicle width. Indian J Crit Care Med. 2007;11:192-7.

48. Thomason JW, Ely EW, Chiles C, Ferretti G, Freimanis RI, Haponik EF. Appraising pulmonary edema using supine chest roentgenograms in ventilated patients. Am J Respirat Crit Care Med. 1998;157(5 Pt 1):1600-8.

49. Wichansawakul S, Vilaichone W, Tongyoo S, Permpikul C, Wonglaksanapimol S, Daengnim K, et al. Evaluation of correlation between vascular pedicle width and intravascular volume status in Thai critically ill patients. J Med Assoc Thai. 2011;94 Suppl 1:S181-187.

50. Iqbal M, Ahmed R, Al Balas H, Gharard SU, Alotaibi FD. Left atrial emptying fraction correlation with vascular pedicle width in patients with normal systolic function. J Coll Physicians Surg Pak. 2006;16(5):320-3.

51. Aloizos SLG, Maragiannis D, Tsigou E, Aravosita P, Evodia E. Comparison of vascular pedicle width and PiCCO-derived haemodynamic measurements in patients in a general intensive care unit. Critical Care. 2007;11 Suppl 2:291.

52. Pistolesi M, Milne EN, Miniati M, Giuntini C. The vascular pedicle of the heart and the vena azygos. Part II: Acquired heart disease. Radiology. 1984;152(1): 9-17.

53. Juhl-Olsen P, Frederiksen CA, Sloth E. Ultrasound assessment of inferior vena cava collapsibility is not a valid measure of preload changes during triggered positive pressure ventilation: a controlled cross-over study. Ultraschall Med. 2012;33(2):152-9.

54. Mitaka C, Nagura T, Sakanishi N, Tsunoda Y, Amaha K. Two-dimensional echocardiographic evaluation of inferior vena cava, right ventricle, and left ventricle during positive-pressure ventilation with varying levels of positive end-expiratory pressure. Critical Care Med. 1989;17(3):205-10. 